\title{
Comparative analysis of rock porosity in a selected region in the Carpathians based on laboratory data and well logs
}

\author{
Maciej Barnaś ${ }^{1 *}$ and Edyta Puskarczyk ${ }^{2}$ \\ ${ }^{1}$ Mineral and Energy Economy Research Institute, Polish Academy of Sciences, 31-261 Krakow, \\ Poland \\ ${ }^{2}$ AGH University of Science and Technology, 30-059 Krakow, Poland
}

\begin{abstract}
A comparative analysis of porosity is presented in the article. This was calculated from laboratory measurements and well logs for rocks from a selected region of the Carpathians. Analysis was performed for samples of sandstones, mudstones, shales and carbonates from four boreholes drilled in the Carpathian Foredeep region near Krakow, Poland. In laboratory measurements, porosity was assessed using two methods: helium pycnometry and nuclear magnetic resonance (NMR). Porosity from well logging was calculated from sonic profiling (SPHI). Cross-plots were used, which allowed for the assessment of the degree of correlation between the laboratory and well log data. The results obtained were analysed paying special attention to the relationship with geological structure. Based on the lithological criterion, the correlations turned out to be strong. The repeatability of the results obtained in different wells was verified. The results of the measurements are significant in relation to estimating porosity from well logs using laboratory data.
\end{abstract}

\section{Introduction}

The aim of the work is to compare the porosity of rocks from a selected region in the Carpathians calculated from laboratory methods and from well log SPHI. An evaluation is made of the degree of correlation between the results of laboratory measurements and well logs, based on laboratory measurements of porosity and sonic well log SPHI. Closely related topics were considered by Hartmann et al. [1] and Mason et al. [2], and in Poland (including Carpathian rocks) by Jarzyna [3], Gąsior and Przelaskowska [4] and Krakowska [5].

Well logs are a trustworthy source of data about physical parameters and variability measurements. However they are usually performed at sampling intervals of $10-25 \mathrm{~cm}$. The measured values, even after applying corrections for the borehole, drilling mud, adjacent layers etc., sometimes can diverge from the real values due to poor vertical resolution and small radius of investigation. Laboratory measurements on samples yield accurate results but have a point-based character, therefore can only act as reference results in addition to well

*Corresponding author: maciej.michal.barnas@gmail.com 
logs. Nevertheless it is necessary to underline that laboratory measurements can be performed in conditions that simulate those of the actual deposit (appropriate temperature and pressure).

The characteristics of the survey area, materials and methods are discussed in the initial part of this article. Afterwards the results of the correlation, well logs and laboratory data are outlined.

\section{Survey area characteristics}

The results from four boreholes (denoted as A-1, A-2, A-3 and A-4), drilled in the Carpathian Foredeep in the south-east Poland, were used for the analyses. The boreholes were located at a distance of between 400 and 2000 metres from each other, and were drilled into the same deposit. The deepest well reached a depth of $3000 \mathrm{~m}$, the remaining three were drilled to depths of $1900-2250 \mathrm{~m}$. Miocene deposits (composed of mudstones, claystones and sandstones) and Late Jurassic deposits (limestones and dolomites) were present. Two boreholes were drilled Middle Jurassic deposits (sandstones and limestones) and PermianTriassic strata (mudstones, claystones and sandstones with anhydrite content). Well No. A-4 was drilled into Carboniferous limestones [6].

\section{Materials and methods}

In the case of the SPHI log, described among others by Jarzyna et al. [7], rock porosity is calculated from the Wyllie (1) or Raymer-Hunt-Gardner (2) equations:

$$
\begin{aligned}
& S P H I=\frac{\Delta t_{\log }-\Delta t_{m a}}{\Delta t_{f}-\Delta t_{m a}} \\
& S P H I=\frac{\Delta t_{\log }-\Delta t_{m a}}{\Delta t_{\log }}
\end{aligned}
$$

where:

$\Delta t_{\log }$ - travel time measured using sonic log,

$\Delta t_{m a}$ - travel time in rock matrix,

$\Delta t_{f}$ - travel time in fluid.

The porosity of rocks was assessed using two laboratory methods: helium pycnometry and nuclear magnetic resonance (NMR). During the pycnometry measurements, a sample was placed in a chamber with a calibrated volume and a gas (usually helium) is injected in. The difference between the volumes of the chamber and the gas provides the volume of the solid rock component. With the known mass and volume of the sample, it is possible to calculate the density. In the case of bulk density measurements, substances which cannot fill the smallest diameter pores are used. For the samples analysed in the article, equipment produced by the American Micromeritics company was used and that diameter was set at 25 nanometers. With density and bulk density, it is easy to calculate effective porosity [8].

Nuclear magnetic resonance uses the phenomenon of the effect of the magnetic field on hydrogen atoms [9]. The results of the surveys are expressed as relaxation time, which is affected by pore size, type of porous medium, movement, water content sealed by clay and that enclosed in capillaries, permeability, residual hydrocarbon saturation and the viscosity of crude oil [8].

Using the available data, descriptive statistics analyses were prepared based on a) wells and b) lithostratigraphical affiliation. Correlation dependences were also checked, and crossplots were made. A sheet of correlation dependences was developed using our own Python scripts, using libraries NumPy and SciPy [10], pandas [12] and Matplotlib [13]. Scripts were 
performed based on source codes which were placed in the thesis [14] and were shared on the Internet platform GitHub [14].

The first script (used both in laboratory data analyses and by arranging them with the well $\operatorname{logs}$ ) imports from .csv files, laboratory data - depth of collecting, values of porosity from two methods, borehole from which the sample originated and lithostratigraphical layer from which the sample was collected. Afterwards, using the least squares criterion; a linear regression along with the coefficient determinant $\mathrm{R}^{2}$, was calculated. The drawing of crossplots was the last stage of the process. The second script was used for importing well log values from .las files and deleting error values. As the results of laboratory measurements have a point character and well logs are continuous, the script arranges well log data with the corresponding laboratory data and saves output results to a .csv file, which can be used in the first script.

78 cylindrical samples, $10-15 \mathrm{~cm}$ in height, were available, including:

- 19 for well A-1, from a depth range of $1591-2245 \mathrm{~m}$

- 6 for well A-2 well, from a depth range of $2000-2045 \mathrm{~m}$

- 17 for well A-3 from a depth range of $1698-1816 \mathrm{~m}$

- 36 for well A-4 from a depth range of $1678-2997 \mathrm{~m}$.

Regarding the geological structure, the number of samples from each lithostratigraphical layer was as follows:

- Neogene -9

- Late Jurassic - 46

- Middle-Jurassic - 6

- Permian-Triassic -7

- Carboniferous - 12 .

\section{Results and analyses}

\subsection{Helium pycnometry and nuclear magnetic resonance}

The total porosity of the core samples was measured twice using helium pycnometry and nuclear magnetic resonance. The correlation plot is shown in Fig. 1. The correlation is very good and the coefficient $\mathrm{R}^{2}$ is very high ( $86 \%$ for the whole dataset). Three outlying samples were observed, with significant deviations from the regression line. They come from different boreholes (A-1 and A-2), and from different lithostratigraphic units (Neogene and Late Jurassic). Probably these two factors did not affect the results. For these samples, much higher total porosity was obtained from the NMR measurement. This is a confirmation of the trend observed for the entire set of samples - the value of the NMR porosity is greater than that of the helium pycnometry. It is most likely that this is due to the presence of bound water or isolated pores that are observable during NMR measurements. The best fit is for wells A4 and A-1 (excluding one sample). 

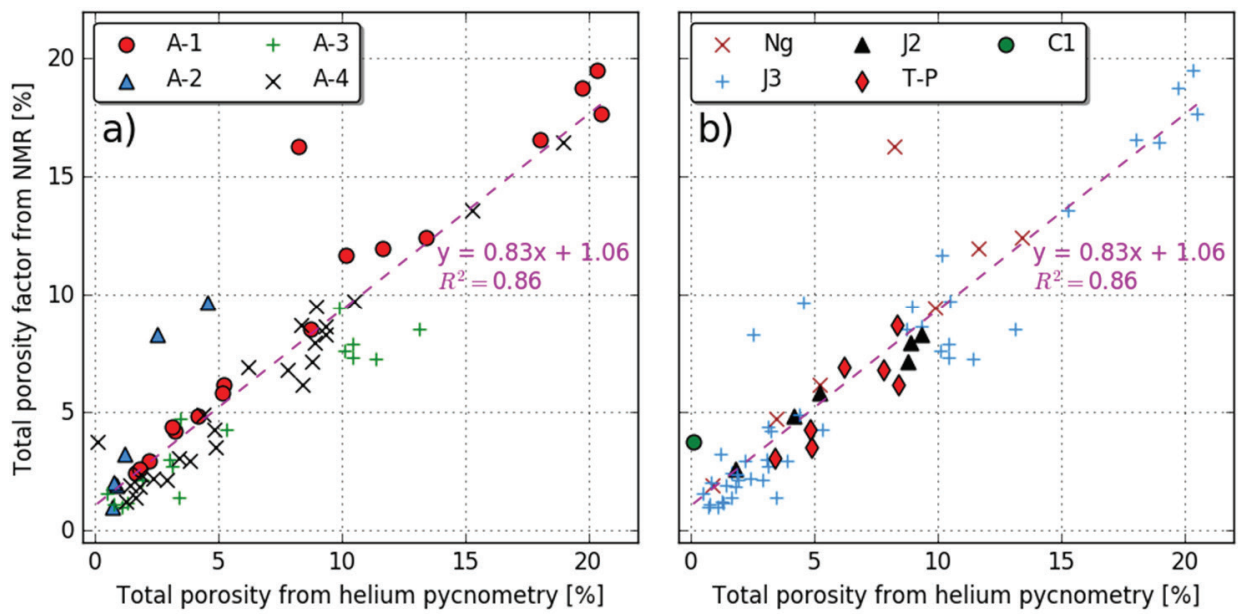

Fig. 1. Correlation of total porosity determined by pycnometer and using nuclear magnetic resonance. The shape and colour of the points differ due to the origin of the sample from a given well (a) or the lithostratigraphic unit to which it belongs: $\mathrm{Ng}$ - Neogene, J3 - Late Jurassic, J2 -Middle Jurassic, T-P - Triassic-Permian, C1 - Carboniferous (b); vertical scale common to both drawings.

\subsection{Porosity parameter vs. porosity}

The relationship of the porosity parameter $P_{p}$ to porosity $p$ is widely used [16]. Fig. 2 shows the log-log comparison. Using the formula (3), the pore structure index $m$ was calculated:

$$
P_{p}=A \cdot p^{-m}
$$

where:

$P_{p}$ - porosity parameter

$p$ - porosity [\%]

The size of $m$ increases with the complexity of the pore structure and the degree of cementing.

The porosity parameter was calculated by measuring the electrical resistance of the cores. Its value is compared with the porosity parameter. For the pycnometry results, the calculated $m$ index was 1.09 , with a determination coefficient of $78 \%$. However, for measurements using nuclear magnetic resonance, the calculated $m$ value is 1.35 , with a determination factor of $72 \%$. In both cases the samples from the A-1 borehole have the best fit to the regression line. The presence of samples which diverge from the regression line can be the result of changes in pore diameter and pore size [16]. As far as lithostratigraphic division is concerned (Fig. 2b), only the Carboniferous has a small coefficient of determination. The other lithologies have a very good match (coefficient of determination between 76 and 95\%) and the index of pore structure varies from 1.02 to 1.78 . 

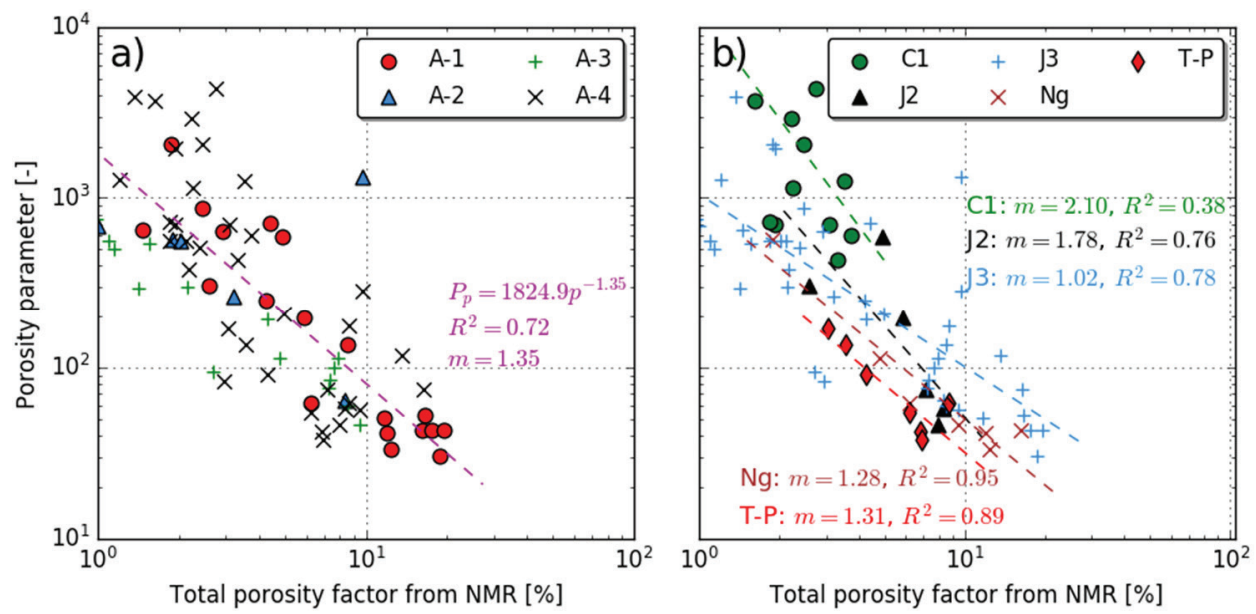

Fig. 2. Determination of the porosity parameter obtained from measurements using nuclear magnetic resonance. The shape and colour of the points are different due to the origin of the sample from the well (a) or the lithostratigraphic unit to which it belonged: $\mathrm{Ng}$ - Neogene, J3 - Late Jurassic, J2 Middle Jurassic, T-P - Triassic-Permian, C1 - Carboniferous (b); vertical scale common to both drawings.

\subsection{Comparison of porosity determined from laboratory measurements and the SPHI well log}

The last stage was the comparison of laboratory tests with corresponding well logs. For this purpose, a SPHI log was used. It shows porosity calculated on the basis on either of the two equations: (1) or (2). In the case of the presence of oil or gas, adjustments need to be made in equations, as they increase the measured travel time.

Considering the above formulae, it is necessary to set the travel time in the rock matrix. In the case of laboratory measurements, the travel time is determined for a specific rock matrix. In the case of well logs, the travel time can be determined for a few rock matrix. This effect can cause discrepancies between SPHI and laboratory measurements, shown in the Fig. 3.

Fig. 3 shows the comparison of SPHI with porosity from laboratory measurements using pycnometry (a, b) and NMR (c, d). Only points from the Late Jurassic, with SPHI values greater than zero, were used to calculate the linear regression. The correlation is quite good - the coefficient of determination varies between 58 and $61 \%$.

\subsection{Comparison of data from well logs and laboratory measurements}

Fig. 4 shows the comparison of the results of other logs with the results of laboratory measurements, after depth correction, for the specific interval at the border of the Neogene and the Jurassic. It is evident that the results of density measurements with the density log (RHOB) and porosity with the SPHI, porosity from density (DPHI) and neutron porosity (NPHI) logs are the best matched. For electrical logs and radioactive content, there are some differences between the laboratory data and well logs, while the relative variations of these values overlap. 

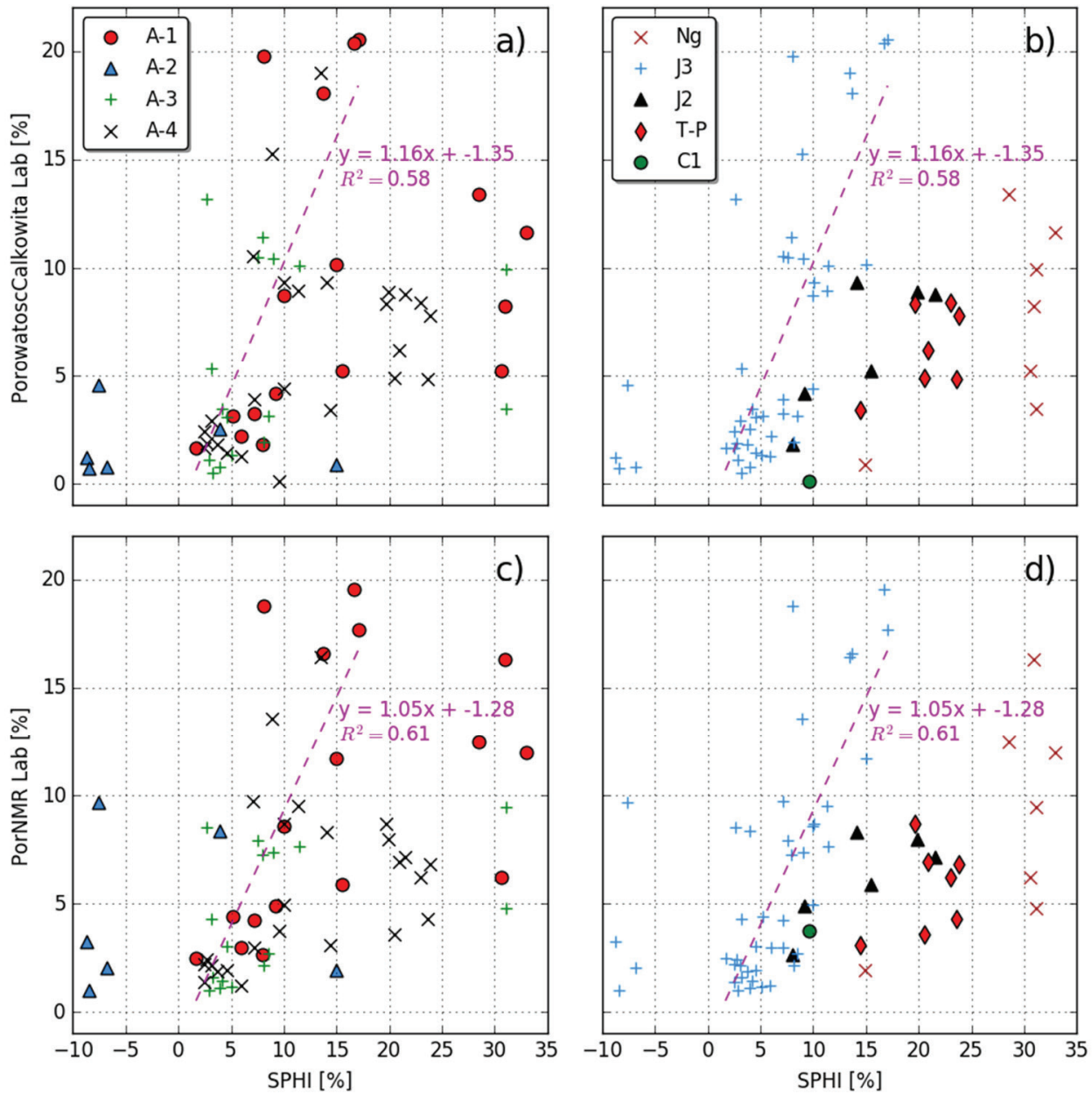

Fig. 3. Comparison of SPHI log results and porosity results measured using pycnometry $(a, b)$ and NMR (c, d). Linear regression was calculated using only the results for Upper Jurassic samples for which the SPHI value is greater than zero. The shape and colour of the points differ due to the origin of the sample from a given borehole (a, c) or belonging to a lithostratigraphic unit: $\mathrm{Ng}$ - Neogene, $\mathrm{J} 3$ -Late Jurassic, J2 - Middle Jurassic, T-P - Triassic-Permian, C1 - Carboniferous (b,d).

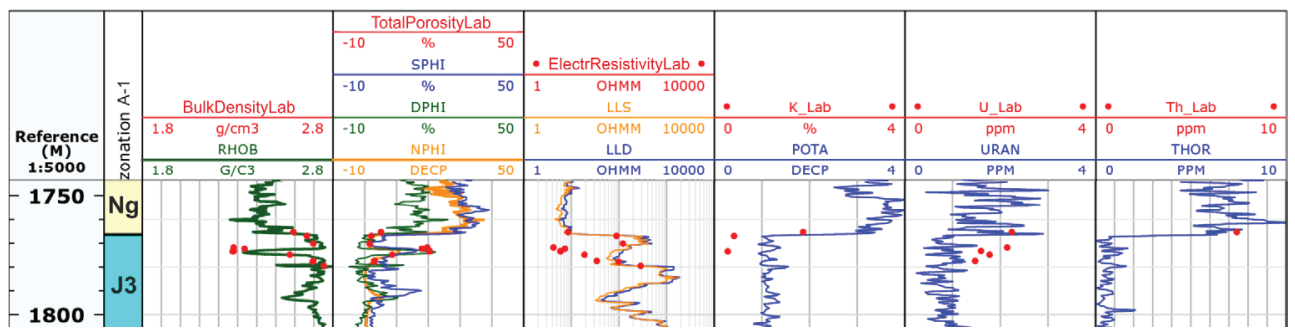

Fig. 4. Comparison of the results of well logs (curves) and laboratory data (red points) for selected intervals from well A-1. 


\section{Summary}

The aim of the study was to carry out a comparative analysis of the results of laboratory measurements and well logs. In order to ensure the right amount of data for the analysis, four boreholes were chosen close to each other with similar lithostratigraphy. Cross-plots were made using Python scripts, along with libraries for statistical calculations. They were used to verify not only the existence and power of correlation between the two methods, but also to evaluate the effect of the origin of the sample from the lithostratigraphic unit and the reproducibility of the results in different wells.

In the case of total porosity, the results of two laboratory measurements (helium pycnometry and NMR experiment) were compared. A very strong correlation demonstrates the effectiveness and repeatability of both. The last step was the analysis of the laboratory data compared to the well $\operatorname{logs}$ - in this case SPHI. The correlation is good, but only for individual lithostratigraphic units. This is due to the calculation of the SPHI value, where it is necessary to set the interval time in the rock matrix. Accepting one value for the entire well has the effect that for some intervals the results will be close to the real porosity, and for others it will vary greatly from one to the other.

In conclusion, laboratory measurements are a very good addition to the well logs, and may be useful for both correlation and calibration of well logs. However, the vertical resolution of the methods being compared and their results and other possible discrepancies resulting from the measurement method need to be taken into account. When correlating the results and their interpretation, knowledge of the method of measurement and calculation of the quantities analysed is needed, and hence also of the potential differences in the results of the measurement.

The authors thank PGNiG SA for providing geological information, well logs and laboratory data. The analyses used in the article were undertaken as a part of Maciej Barnas' Master's of Sciences Thesis.

\section{References}

1. A. Hartmann, V. Rath, C. Clauser, Int. J. Rock Mech. Min. 7-8, 42, 1042-1055 (2005) doi: 10.1016/j.ijrmms.2005.05.015

2. H. E. Mason, M. M. Smith, Y. Hao, S. A. Carroll, Enrgy Proced. 63, 3089-3096, doi: 10.1016/j.egypro.2014.11.332 (2014)

3. J. Jarzyna, Analysis of density and porosity measurements on cores and results of density log and Estymacja calculations in the selected wells in the West Carpathians, Geologia 4/1, 33, 39-58 (in Polish) (2011)

4. I. Gąsior, A. Przelaskowska, Acta Geophys. 4, 62, 785-801 (2014) doi: 10.2478/s11600014-0204-y

5. P. Krakowska, Determination of reservoir potential of sedimentary rocks of the Precambrian and Palaeozoic age on the basis of the results of laboratory tests and well $\operatorname{logs}$, PhD Thesis (In Polish) (AGH University of Science and Technology, Kraków 2014)

6. A. Indyk, I. Molenda, P. Pasek, J. Florczak, D. Czarnecka, A. Należniak, The results of interpretation well logs performer using DDL-D Halliburton set (final report), well: A-4 (name of the well was modified) (unpublished, in Polish) (Geofizyka Kraków Sp. z o.o. 2011)

7. J. Jarzyna, M. Bała, T. Zorski, Methods of well logging - acquisition and interpretation (in Polish), (Wyd. AGH, Kraków 1999) 
8. J. Zalewska, D. Cebulski, M. Dohnalik, A. Fuks-Kopiejka, J. Kaczmarczyk, S. Kowalska, A. Przelaskowska, J. Kiernicki, Specialized service research for the well: A4 (name of the well was modified), Task I: Specialized measurements of geophysical parameters of cores and muds with interpretation (unpublished, in Polish) (Oil and Gas Institute - National Research Institute, Kraków 2011)

9. E. Puskarczyk, Assessment of reservoir properties of rocks using the nuclear magnetic resonance experiment, $\mathrm{PhD}$ Thesis (in Polish) (AGH University of Science and Technology, Kraków 2011)

10. P. Janusz, Crossplots as an instrument of well logging interpretation. Bachelor's Thesis, (in Polish) (AGH University of Science and Technology, Kraków 2016)

11. S. van der Walt, C. Colbert, G. Varoquaux, Comput. Sci. Eng. 13, 22-30 (2011) doi:10.1109/MCSE.2011.37

12. W. McKinney, Data Structures for Statistical Computing in Python, Proc. of the 9th Python in Science Conference (2010)

13. J.D. Hunter, Comput. Sci. Eng. 9, 3, 90-95 (2007) doi:10.1109/MCSE.2007.55

14. M. Barnaś, Comprehensive analysis of laboratory data and well logs for selected reservoir, Master's Thesis (in Polish) (AGH University of Science and Technology, Kraków 2016)

15. M. Barnaś, ArticleWOC2017, GitHub repository: https://github.com/barneygf/ArticleWOC2017 (access: 2017-09-21) (2017)

16. J. Zalewska, D. Cebulski, Results of laboratory measurements of electrical properties of rocks, Nafta-Gaz 4, 66, 251-256 (in Polish) (2010) 